Article

\title{
Alleviating the Mechanical and Thermal Degradations of Highly Sulfonated Poly(Ether Ether Ketone) Blocks via Copolymerization with Hydrophobic Unit for Intermediate Humidity Fuel Cells
}

\author{
Ae Rhan Kim ${ }^{1, *}$, Mohanraj Vinothkannan ${ }^{2}$, Chul Jin Park ${ }^{2}$ and Dong Jin Yoo ${ }^{2,3, *}$ \\ 1 Department of Bioenvironmental Chemistry and R\&D Center for CANUTECH, Business Incubation Center, \\ Chonbuk National University, Jeollabuk-do 54896, Republic of Korea \\ 2 Graduate School, Department of Energy Storage/Conversion Engineering, Hydrogen and Fuel Cell \\ Research Center, Chonbuk National University, Jeollabuk-do 54896, Republic of Korea; \\ vinothkannanram@gmail.com (M.V.); top_pcj@hanmail.net (C.J.P.) \\ 3 Department of Life Science, Chonbuk National University, Jeollabuk-do 54896, Republic of Korea \\ * Correspondence: canutech@hanmail.net (A.R.K.); djyoo@jbnu.ac.kr (D.J.Y.)
}

Received: 17 November 2018; Accepted: 3 December 2018; Published: 5 December 2018

\begin{abstract}
In this contribution, sulfonated poly(ether ether ketone) (SPEEK) is inter-connected using a hydrophobic oligomer via poly-condensation reaction to produce SPEEK analogues as PEMs. Prior sulfonation is performed for SPEEK to avoid random sulfonation of multi-block copolymers that may destroy the mechanical toughness of polymer backbone. A greater local density of ionic moieties exist in SPEEK and good thermomechanical properties of hydrophobic unit offer an unique approach to promote the proton conductivity as well as thermomechanical stability of membrane, as verify from AC impedance and TGA. The morphological behavior and phase variation of membranes are explored using FE-SEM and AFM; the triblock (XYX) membranes exhibits a nano-phase separated morphology. Performance of PEFC integrated with blend and block copolymer membranes is determined at $60{ }^{\circ} \mathrm{C}$ under $60 \% \mathrm{RH}$. As a result, the triblock (XYX) membrane has a high power density than blend (2X1Y) membrane.
\end{abstract}

Keywords: sulfonated poly(ether ether ketone); hydrophobic oligomer; mechanical stability; intermediate humidity; cell performance

\section{Introduction}

Polymer electrolyte fuel cells (PEFCs) have efficacy as next-generation energy devices owing to their features of extraordinary energy density from single-step energy conversion and environmental benignity due to low pollutant-emission levels [1-4]. However, PEFCs have faced a high-cost key material dilemma, which is the main factor hindering their widespread utilization. The proton exchange membrane (PEM), the key module of PEFCs, acts as a proton conducting medium [5-8]. At present, Nafion (Dupont) is the most commonly used PEM in industry as it shows high proton conductivity, structural stability, unique micro-morphological structure, and mechanical toughness [9]. The key drawbacks of this membrane, however, are limited proton conductivity while operating under anhydrous environment, synthesis difficulty, environmental unfriendliness, and high cost [10-12]. The two most common methods used to solve these issues are (i) modification of Nafion using other polymers or inorganic compounds and (ii) designing new PEMs that are free of Nafion [13-16]. The former strategy typically suffers due to incompatibility between different components. The second 
approach, which is more favorable for fabricating commercial PEMs at an industrial scale involves investigating non-fluorinated polymers include sulfonated poly(ether ether ketone) (SPEEK) [17], sulfonated poly(imide) [18], sulfonated poly(arylene ether ketone) [19], and sulfonated poly(phenylene sulfone) [20]. Unfortunately, aromatic polymer-based PEMs face an important struggle, i.e., imbalance between membrane conductivity and mechanical toughness [21]. For instance, SPEEK is the most favorable substitute to Nafion owed to its thermal stability, mechanical integrity, modification flexibility, and low cost [22]. Nevertheless, the ionic channels of SPEEK are narrower, disordered, and unconnected; thus, the maximized proton conductivity can only be achieved via increasing the degree of sulfonation (DS) [23]. PEMs with a high DS exhibit poor physical integrity and high water swelling behavior, resulting in rapid degradation of PEFC performance [24]. On other hand, chemical stability is an important factor that is highly confined to SPEEK in general. In $\mathrm{OH}$ and $\mathrm{OOH}$ radical environments, the durability of SPEEK membranes falls to a critically low level due to chemical unzipping of polymer chains. To address the aforementioned issues, various strategies such as introducing cross-linkers, blending hydrophobic polymers, or physically reinforcing with metal-ion scavengers have been proposed to improve durability $[9,25,26]$. Since mechanical brittleness and proton conductivity decline when applying the aforementioned strategies, block copolymerization of SPEEK could retain its full advantages as well as further boost the performance of PEMs. In our previous report, the physical blending of SPEEK with block copolymer exhibited a $10 \%$ increase in ion conductivity [27]. However, physical blending is based on non-covalent interactions that are difficult to ideally arrange two polymer matrixes and construct conducting channels in PEMs. Therefore, a desirable strategy needs to be explored to further increase the ion conductivity of PEMs. Block copolymerization of SPEEK, derived from commercially available PEEK, with a hydrophobic unit is a promising strategy to alleviate the drawbacks existing in the physical blending of PEMs.

Herein, in consideration of the practicability of PEMs, we explored a nucleophilic substitution strategy to synthesize a block structure wherein SPEEK $(X)$ was the hydrophilic unit and fluorinated poly (arylene propane biphenyl) (FPAPB) (Y) was the hydrophobic unit. Further, a series of block structures $(X Y, X Y X$, and $Y X Y)$ were synthesized to determine the best combinations and ratios. These polymers can simply accessible via reported synthetic routes. The acquired block copolymers were intensively characterized as mentioned in literature. Based on these findings, we show that even chemically inter-connecting SPEEK using a hydrophobic unit can be a better approach; thus, the corresponding PEM should be a potential candidate for integration into PEFC devices. Additionally, effects on chemical structure ( $\left.{ }^{1} \mathrm{H}-\mathrm{NMR}\right)$, phase-separation morphology (FE-SEM), and physiochemical properties including thermal and mechanical stability (TGA, DSC, and UTM) and proton conductivity (AC impedance test), were also investigated. To further examine the effect on PEFC performance, an MEA was fabricated, and a polarization curve was investigated.

\section{Materials and Methods}

\subsection{Materials}

Decafluorobiphenyl (DFBP, 98\%) and 4,4'-hexafluoroisopropylidenediphenol (HFIP, 99\%) were acquired from Sigma-Aldrich. Poly(ether ether ketone) (PEEK) pellet was purchased from Victrex. Dimethyl sulfoxide (DMSO, 99.8\%), $\mathrm{N}, \mathrm{N}$-dimethylacetamide (DMAc, 99.8\%), potassium carbonate $\left(\mathrm{K}_{2} \mathrm{CO}_{3}, 99.5 \%\right)$, toluene $(99.8 \%), \mathrm{N}$-methylpyrrolidinone (NMP, 99\%), and tetrahydrofuran (THF, 99\%) were procured from Sigma-Aldrich.

\subsection{Synthesis of Na Salt Form of $X$}

Synthesis of the Na salt form of $X$ was performed as reported in the literature [28]. Commercial PEEK (5 g) and sulfuric acid (95 mL) were added to a $200 \mathrm{~mL}$ two-necked flask equipped with a mechanical stirrer and heated on a hot plate at $50{ }^{\circ} \mathrm{C}$. By changing the reaction time, SPEEK with varied degrees of sulfonation was acquired. After the reaction, the resulting solution was decanted 
into deionized (DI) ice water. The settled-down fibrous product was washed with DI water up to the filtrate reached $\mathrm{pH}$ 7. The dry $\mathrm{X}$ was submerged in $0.1 \mathrm{M} \mathrm{NaCl}$ solution for $24 \mathrm{~h}$ to interchange $\mathrm{H}^{+}$ ions by $\mathrm{Na}^{+}$ions. The $\mathrm{Na}$ salt form of $\mathrm{X}$ was dried again and kept for further usage.

\subsection{Synthesis of $Y$}

$\operatorname{HFIP}\left(2.017 \mathrm{~g}, 6 \times 10^{-3} \mathrm{M}\right), \operatorname{DFBP}\left(2.0 \mathrm{~g}, 6 \times 10^{-3} \mathrm{M}\right), \mathrm{K}_{2} \mathrm{CO}_{3}\left(1.66 \mathrm{~g}, 12 \times 10^{-3} \mathrm{M}\right), \mathrm{DMAc}(11 \mathrm{~mL})$, and toluene $(20 \mathrm{~mL})$ were placed in a clean $100 \mathrm{~mL}$ three-necked round bottomed (RB) flask equipped with a condenser with $\mathrm{N}_{2}$ gas valve, and a magnetic stir bar. The polymerization reaction was carried out at $120-140^{\circ} \mathrm{C}$ (oil bath) under N2 with constant stirring for $3 \mathrm{~h}$. To remove produced water, the temperature of the reaction was increased to $160^{\circ} \mathrm{C}$. The reaction was continued for $24 \mathrm{~h}$ to acquire a light yellow viscous liquid mixture, which was cooled and precipitated in a mixture of DI water, methanol, and acetone. The obtained fibrous precipitate was successively washed with DI water few times and kept in a vacuum oven at $70{ }^{\circ} \mathrm{C}$ for $12 \mathrm{~h}$.

\subsection{Synthesis of Diblock and Triblock Copolymers}

For the preparation of $\mathrm{XY}, \mathrm{Na}$ salt form of $\mathrm{X}\left(0.63 \mathrm{~g}, 4.78 \times 10^{-6} \mathrm{M}, M_{W}=132,000\right), \mathrm{Y}(0.134 \mathrm{~g}$, $\left.4.78 \times 10^{-6} \mathrm{M}, M_{W}=28,000\right)$, potassium carbonate $\left(0.026 \mathrm{~g}, 1.90 \times 10^{-4} \mathrm{M}, M_{W}=138\right)$, DMAc $(9 \mathrm{~mL})$, and toluene $(19 \mathrm{~mL})$ were placed in a three-necked RB flask. The reaction involves two-step process (i) dehydration of system in which the mixture was heated with reflux at $120-140{ }^{\circ} \mathrm{C}$ for $10 \mathrm{~h}$ and (ii) polymerization of oligomers in which the reaction temperature was retained at $160^{\circ} \mathrm{C}$ for $14 \mathrm{~h}$. Finally, the reaction mixture was purified by repeated washing with co-solvent (methanol/acetone/deionized water, 10:1:1, v/v/v) and separated by filtration. To ensure the complete elimination of unreacted hydrophobic oligomers and formation of block copolymer, the product was further washed with dichloromethane. The $X Y X$ and $Y X Y$ polymers were fabricated using a similar strategy by varying the ratio of precursors. For the XYX case, $X\left(1.26 \mathrm{~g}, 9.56 \times 10^{-6} \mathrm{M}, M_{W}=132,000\right), \mathrm{Y}\left(0.134 \mathrm{~g}, 4.78 \times 10^{-6} \mathrm{M}\right.$, $\left.M_{W}=28,000\right)$, potassium carbonate $\left(0.0524 \mathrm{~g}, 3.80 \times 10^{-4} \mathrm{M}, M_{W}=138\right)$, DMAc $(11 \mathrm{~mL})$, and toluene $(19 \mathrm{~mL})$ were used. For the YXY case, $\mathrm{X}\left(0.63 \mathrm{~g}, 4.78 \times 10^{-6} \mathrm{M}, M_{W}=132,000\right)$ and $\mathrm{Y}(0.269 \mathrm{~g}$, $\left.9.56 \times 10^{-6} \mathrm{M}, M_{W}=28,000\right)$, potassium carbonate $\left(0.0524 \mathrm{~g}, 3.80 \times 10^{-4} \mathrm{M}, \mathrm{M}_{W}=138\right)$, DMAc $(11 \mathrm{~mL})$, and toluene $(19 \mathrm{~mL})$ were used.

\subsection{Membrane Preparation}

A preferred amount of $\mathrm{X}, \mathrm{XY}, \mathrm{XYX}$, or $\mathrm{YXY}$ was added to DMF, and the resulting suspension was sonicated to acquire a homogeneous solution. After further stirring for $72 \mathrm{~h}$ at $60{ }^{\circ} \mathrm{C}$, the mixture was cast onto a glass plate and kept in a $120^{\circ} \mathrm{C}$ oven for $6 \mathrm{~h}$ for solvent evaporation. Similarly, the blend membrane was prepared by blending $X$ and $Y$ in DMF with the ratio of 1:1, 2:1, or 1:2. The acquired membranes were changed to acidic form by submerging in $1 \mathrm{M} \mathrm{H}_{2} \mathrm{SO}_{4}$ and then rinsed in DI water to detach free acids. Figure 1 shows the digital photographs of the XYX membrane wherein the fabricated $\mathrm{XYX}$ membrane is flexible without any significant visible defects.
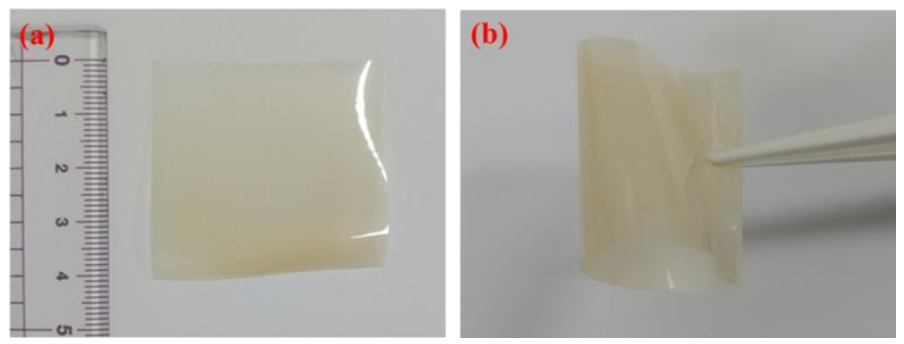

Figure 1. Digital photographs XYX membrane (a) flat view and (b) folded view. 


\section{Characterizations}

The as-made membranes were analyzed with field-emission scanning electron microscopy (FE-SEM) (SUPRA 40VP, ZEISS, city, state, country), atomic force microscopy (AFM) (multimode-8 model, Bruker, city, state, country), Fourier transform nuclear magnetic resonance spectroscopy (FT-NMR), small angle X-ray scattering (SAXS) (EMPYREAN, Malvern Panalytical, city, state, country), thermogravimetric analyzer (TGA) (TA-instruments-Q20), differential scanning calorimetry (DSC) (TA-instruments-Q50), and universal tensile machine (UTM) (model 5565, Lloyd, Fareham, UK).

\section{Measurements}

\subsection{Water Uptake}

Water retention properties of membranes were measured at $30^{\circ} \mathrm{C}$. The dry membranes were pre-weighed and submerged in DI water for $24 \mathrm{~h}$ at $30^{\circ} \mathrm{C}$. Next, the membranes were removed, wiped with tissue paper, and weighed again [29]. The water uptake values were calculated from mass difference of dry and wet membranes with the following equation

$$
\text { Water uptake (\%) }=\left[\frac{M_{w e t}-M_{d r y}}{M_{d r y}}\right] 100
$$

The wet membrane mass ( $M_{\text {wet }}$ in grams) and dry membrane mass $\left(M_{d r y}\right.$ in grams) were acquired using a Denver four digit counter balance (Model: S-234) with a precision of $\pm 0.01 \mathrm{mg}$.

\subsection{Dimensional Stability}

Dimensional stability of membranes was determined from the volume change before and after uptake of water. The following equation was used to calculate the swelling ratio

$$
\text { Swelling ratio }(\%)=\left[\frac{V_{w e t}-V_{d r y}}{V_{d r y}}\right] 100
$$

where $V_{d r y}$ and $V_{\text {wet }}$ are the volumes of the membrane samples before and after water uptake, respectively.

\subsection{Contact Angle}

To determine the wettability of membranes, contact angle measurements were performed using a drop shape analyzer (DSA10, Kruss GmbH, city, Germany).

\subsection{Proton Conductivity}

Temperature dependent conductivity of hydrated samples was scrutinized using alternating current impedance spectroscopy (Sci Tech instrument equipped with Keithley-2400 source meter). The measurement was performed in a Bekk-Tech cell in which the membrane was placed across four Pt electrodes [30]. The conductivity was calculated from the equation given below

$$
\sigma\left(m S c m^{-1}\right)=\left[\frac{L}{R T W}\right]
$$

where the distance between Pt probes is $L(\mathrm{~cm})$, while ionic resistance of the cell is $R(\Omega)$, and the width and thickness of the membrane sample are designated as $W(\mathrm{~cm})$ and $T(\mathrm{~cm})$, respectively. Membrane reproducibility toward conductivity was verified by performing the measurement twice. 


\section{Membrane Electrode Assembly (MEA) Preparation and PEFC Testing}

Carbon papers attached with diffusion layers were employed as electrodes. For preparation of the anode layer or cathode layer, an appropriate amount of $\mathrm{Pt} / \mathrm{C}$ catalyst $(40 \%$, Johnson Matthey Co.) was dispersed in ionomer solution (isopropyl alcohol with Nafion ionomer) and applied onto the carbon paper surface using spray gun. A loading Pt catalyst was controlled to be $0.3 \mathrm{mg} \mathrm{cm}$ for both electrodes. MEAs with an active surface area of $5 \mathrm{~cm}^{2}$ were acquired via sandwiching the membrane between anode and cathode and subsequently pressed $14,000 \mathrm{psi}$ at $90{ }^{\circ} \mathrm{C}$ for $3 \mathrm{~min}$. Each acquired MEA was then fitted with gaskets and integrated in a PEFC cell fixture. Afterwards, PEFC cell fixture was connected with Horizon (Sci Tech, South Korea) test station and performance curves were extracted as a function of current density. The $\mathrm{H}_{2} / \mathrm{O}_{2}$ PEFC was operated at a flow rate of $100 \mathrm{ccm} \mathrm{min}^{-1}$ for $\mathrm{H}_{2}$ and $400 \mathrm{ccm} \mathrm{min}^{-1}$ for $\mathrm{O}_{2}$ at $60^{\circ} \mathrm{C}$ and $60 \% \mathrm{RH}$.

\section{Results and Discussion}

\subsection{Synthesis and Structural Properties}

Block copolymers were produced by polycondensation and polymerization methods as described previously. As the concentration of $\mathrm{SO}_{3} \mathrm{H}$ groups is directly related to conductivity, to study the correlation, the content of the sulfonated block with a range of lengths was also considered. SPEEK and hydrophobic oligomer were utilized as precursors for synthesis of multi-block copolymers (XY, $X Y X$, and $Y X Y$ ). To determine the chemical structures, the as-made $X, Y$, triblock copolymers ( $X Y X$ and $\mathrm{YXY}$ ), and diblock copolymer (XY) were dissolved in DMSO- $\mathrm{d}_{6}$ solvent and analyzed by ${ }^{1} \mathrm{H}-\mathrm{NMR}$ spectroscopy (Figure 2a,b). X peaks are observed from 6.9 to $7.9 \mathrm{ppm}$ in the ${ }^{1} \mathrm{H}-\mathrm{NMR}$ spectrum, which are associated with aromatic protons. While the successive grafting of $\mathrm{SO}_{3} \mathrm{H}$ groups in $\mathrm{X}$ could be endorsed from the peak at $7.5 \mathrm{ppm}$. By evaluating the ratio of peak area at $7.5 \mathrm{ppm}$ to the total peak area of remaining peaks, the DS of SPEEK was determined. Triblock copolymers (XYX) had significant signals in the range of 6.9 to $7.9 \mathrm{ppm}$, which arose from the aromatic protons of SPEEK and the hydrophobic units. In other hand, the decrement of signal intensity at $7.3 \mathrm{ppm}$ in the order of YXY, XY, and $X Y X$ indicates the decrement in hydrophobic ratio in the polymer. It is noteworthy that the $X Y X$ polymer had a very small quantity of hydrophobic component (Figure $2 b$ ). As shown in Table 1, the SPEEK $(X)$ and hydrophobic polymer $(Y)$ had considerable molecular weights $\left(M_{w}\right)$ of 131,700 and 28,000 , respectively. The ratio of $X$ and $Y$ in the triblock polymer was controlled to be 2:1 or 1:2, and the diblock polymer was controlled to be 1:1 molar ratio. The average $M_{w}$ values of $X Y X, X Y$, and $Y X Y$ were $183,400,155,700$, and 179,700 respectively. The PDI $\left(M_{w} / M_{n}\right)$ values for $X Y X, X Y$, and YXY were 4.0, 3.6, and 3.5, respectively. In addition, the morphology of the as-made membranes was verified by SAXS, and the ionic cluster dimensions are compared in Figure S1. The SAXS patterns revealed similar morphologies for the $\mathrm{XYX}, \mathrm{XY}$, and $\mathrm{YXY}$ membranes, which differed from the blend membrane. 


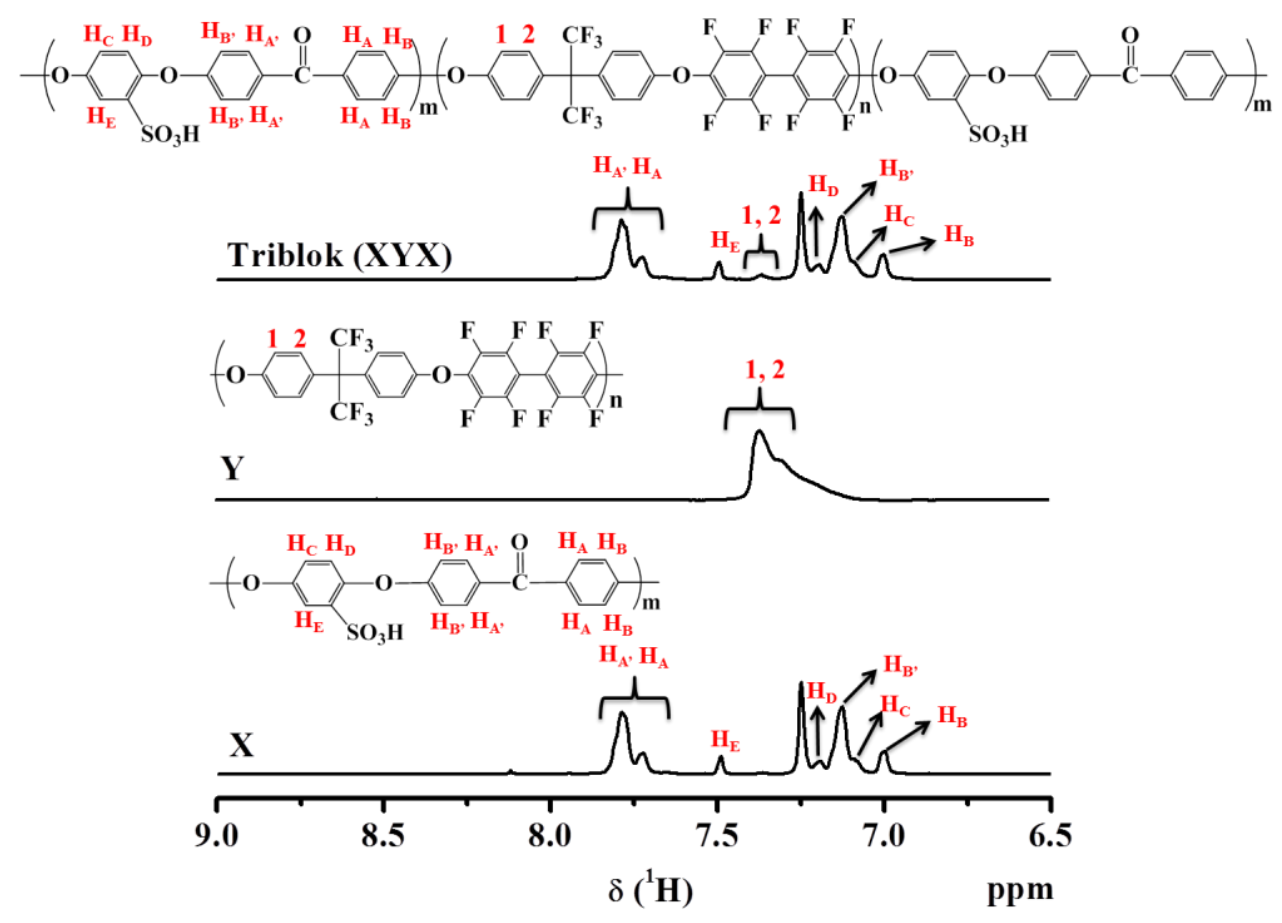

(a)

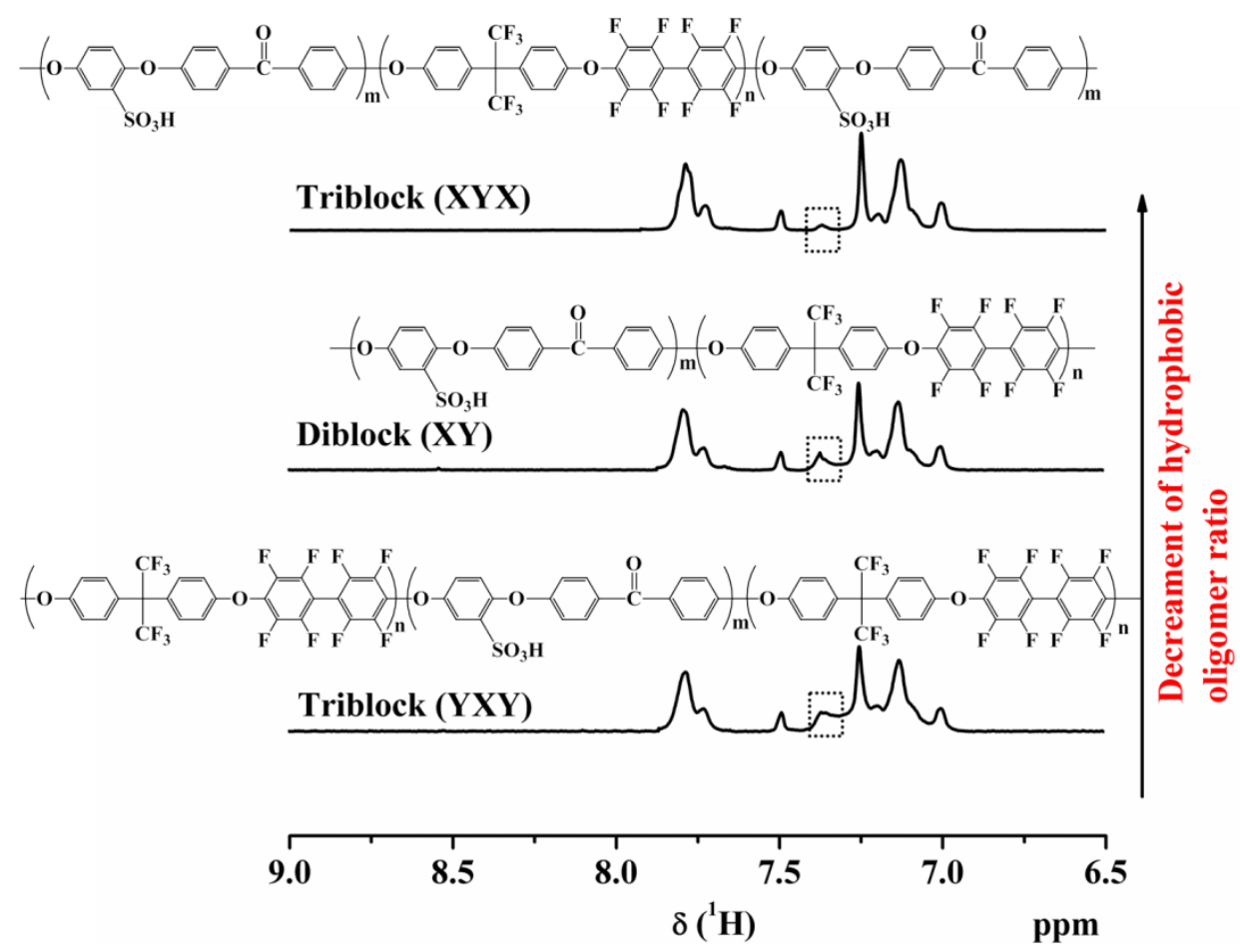

(b)

Figure 2. (a) ${ }^{1} \mathrm{H}-\mathrm{NMR}$ spectra of $\mathrm{X}, \mathrm{Y}$ and $\mathrm{XYX}$. (b) ${ }^{1} \mathrm{H}-\mathrm{NMR}$ spectra of block copolymers. 
Table 1. GPC analysis of prepared polymers

\begin{tabular}{cccccc}
\hline Polymer & Area $(\mathbf{\%})$ & $\boldsymbol{M}_{\boldsymbol{n}}$ & $\boldsymbol{M}_{\boldsymbol{w}}$ & $\boldsymbol{M}_{\boldsymbol{z}}$ & $\boldsymbol{M}_{\boldsymbol{w}} / \boldsymbol{M}_{\boldsymbol{n}}$ (PDI) \\
\hline X & 92.7 & 50,600 & 131,700 & 307,200 & 2.6 \\
Y & 70.5 & 6600 & 28,000 & 66,300 & 4.2 \\
XYX & 94.8 & 45,700 & 183,400 & 605,000 & 4.0 \\
XY & 95.8 & 42,900 & 155,700 & 458,200 & 3.6 \\
YXY & 96.5 & 50,400 & 179,700 & 546,400 & 3.5 \\
\hline
\end{tabular}

\subsection{Morphological Behaviors}

FE-SEM morphologies of as-made $X Y X, X Y$, and $Y X Y$ type membranes are given in Figure 3, each of which has a rough surface and uniform hydrophilic-hydrophobic phase-separation. In $X$ membrane (Figure 3a), two types of patterns can be clearly observed: (i) hydrophilic cluster and (ii) hydrophobic cluster. When compared to $\mathrm{X}$, phase contrast in the $\mathrm{XY}$ membrane is found to be increased due to two dissimilar material domains (Figure $3 b$ ). The higher $\mathrm{SO}_{3} \mathrm{H}$ density in the $\mathrm{X}$ part produced brighter domains, while the darker regions indicate the hydrophobic component [31]. The degree of phase-separation varies for $X Y, X Y X$, and $Y X Y$ due to the various ratios of hydrophilic and hydrophobic components. As shown in Figure 4, the blend (2X1Y) shows the aggregated particles due to the immiscibility of hydrophilic and hydrophobic units (Figure 4e), whereas the triblock (XYX) membrane exhibits the homogeneous distribution caused by the covalent bond formation to make the single polymer unit (Figure 4c). In AFM (Figure 5), a higher quantity of phase-separation was detected for the $X Y$ type membrane compared to $X Y X$ and $Y X Y$ type membranes. This is because of the equal ratio of hydrophilic and hydrophobic oligomers. The water contact angle of the membranes decreased according to increasing the $\mathrm{X}$ ratio in the block structure (Figure 6).

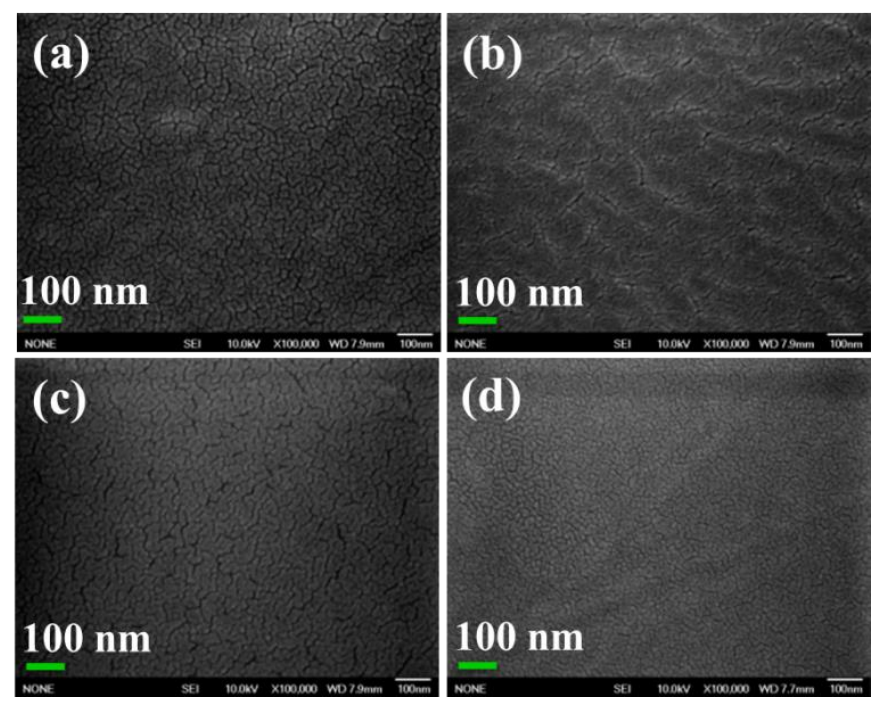

Figure 3. FE-SEM images of membranes of (a) X;(b) XY; (c) XYX; and (d) YXY. 


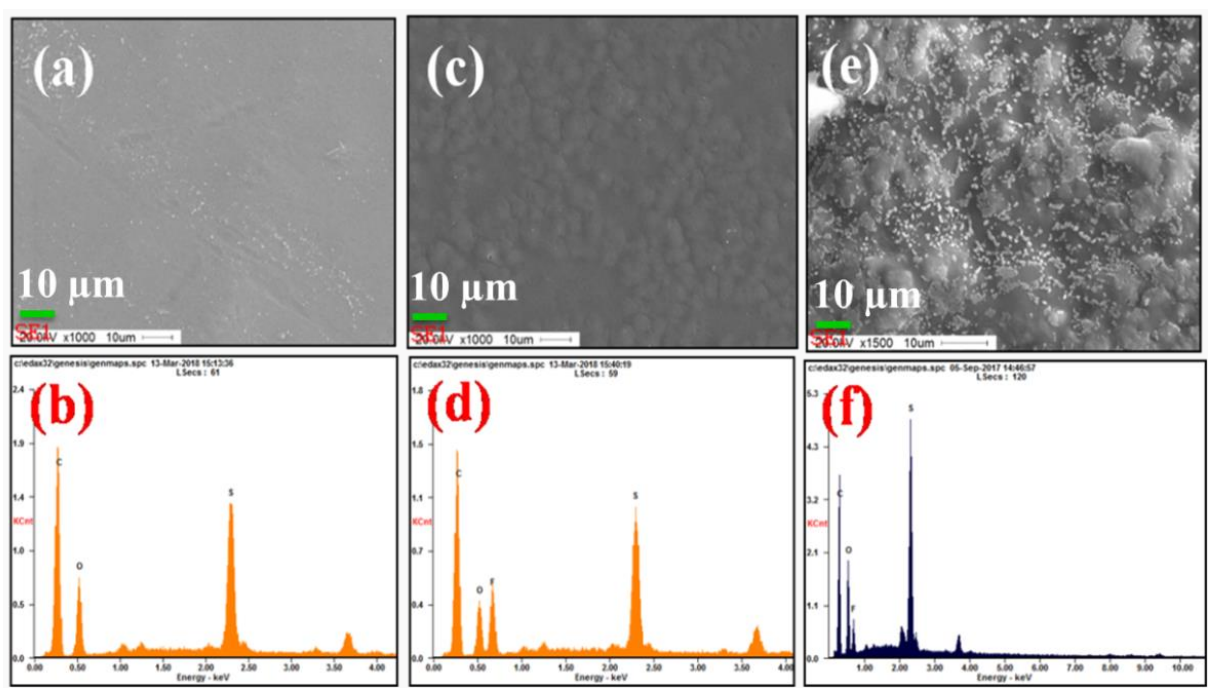

Figure 4. FE-SEM images and EDX spectra of membranes of $(\mathbf{a}, \mathbf{b}) \mathrm{X}$; (c,d) triblock $(\mathrm{XYX}) ;(\mathbf{e}, \mathbf{f})$ blend $(2 \mathrm{X} 1 \mathrm{Y})$.
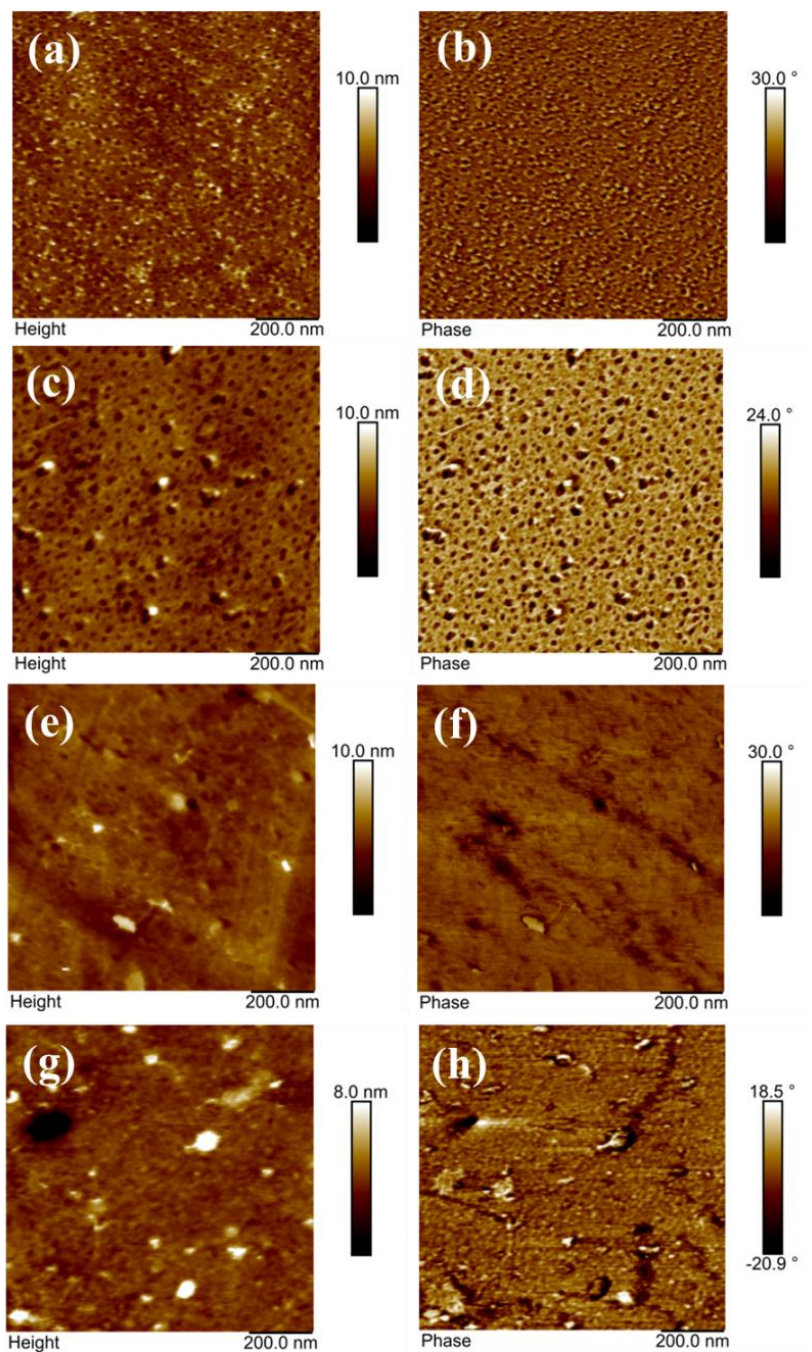

Figure 5. AFM height and phase images of membranes of $(\mathbf{a}, \mathbf{b}) \mathrm{X} ;(\mathbf{c}, \mathbf{d}) \mathrm{XY} ;(\mathbf{e}, \mathbf{f}) \mathrm{XXY}$; and $(\mathbf{g}, \mathbf{h}) \mathrm{YXY}$. 


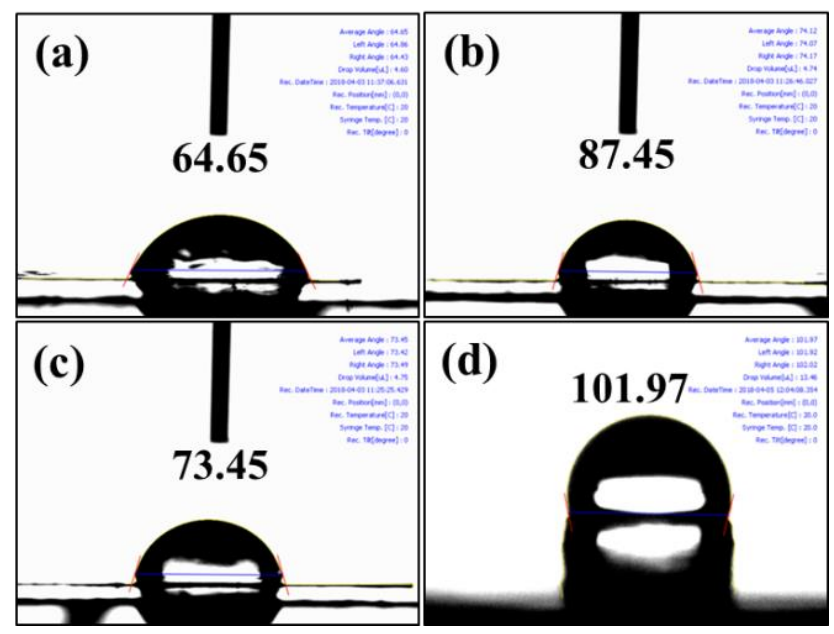

Figure 6. Water contact angle images of (a) X; (b) XY; (c) XYX; and (d) YXY.

\subsection{Thermal Stabilities}

Figure 7 exhibits TGA curves for determining the percent weight loss. At a temperature of $800{ }^{\circ} \mathrm{C}$, the SPEEK membrane had a residual weight of $43.6 \%$, which may be due to rapid decomposition of the main skeleton, while the $X Y X$ membrane had a residual weight of $45.8 \%$, the $X Y$ membrane had a residual weight up to $51.9 \%$, and the YXY membrane had a residual weight of $53.07 \%$ at the same temperature. These results reveal that the $X Y X$ and $Y X Y$ membranes are thermally less stable compared to the YXY membrane. DSC curves of the as-made membranes showed considerable endothermic inflection $\left(\mathrm{T}_{\mathrm{g}}\right)$ values, all between $192-218^{\circ} \mathrm{C}$ (Figure $\mathrm{S} 2$ ). The $\mathrm{XYX}$ type had a higher $\mathrm{T}_{\mathrm{g}}$ compared to the other membranes. In general, the $\mathrm{T}_{\mathrm{g}}$ of a membrane increases with the number of ionic sites on the polymer chains because of an ionomer effect. The $\mathrm{T}_{\mathrm{g}}$ of the $\mathrm{XYX}$ membrane was $218.15^{\circ} \mathrm{C}$, which is greater by a factor of 1.01 and 1.07 compared to the $X Y\left(216.13^{\circ} \mathrm{C}\right)$ and $\mathrm{YXY}\left(204.15^{\circ} \mathrm{C}\right)$, respectively. Meanwhile the great density of $\mathrm{SO}_{3} \mathrm{H}$ sites increases the molecular bulkiness of the polymers, the $\mathrm{T}_{\mathrm{g}}$ of membranes increases according to the bulkiness of the membrane. A high density of $\mathrm{SO}_{3} \mathrm{H}$ groups generates large numbers of internal hydrogen bonds that restrict reorganization of polymer chains during heating, resulting in a decreased $\mathrm{T}_{\mathrm{g}}$ for the $\mathrm{XY}$ and $\mathrm{YXY}$ membranes.

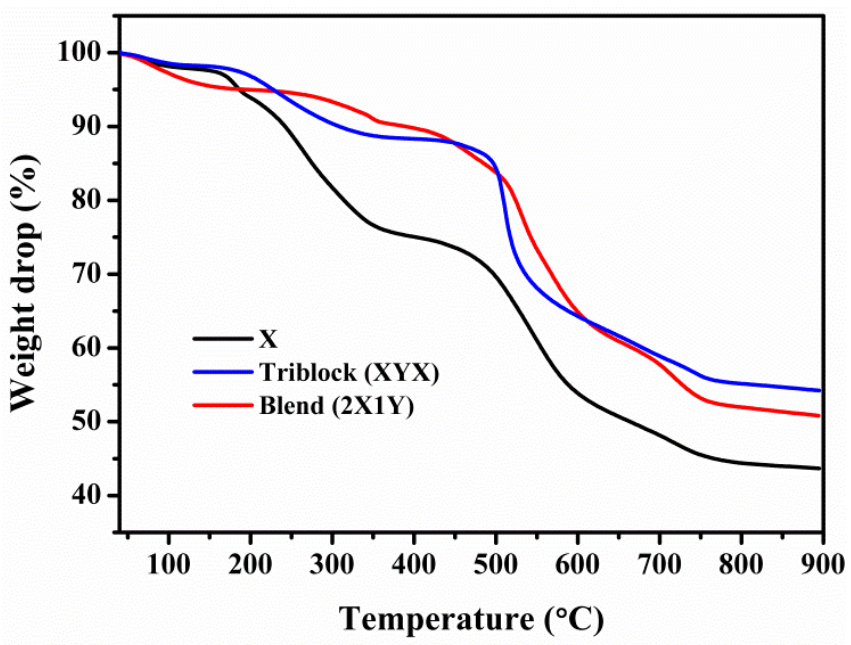

Figure 7. TGA curves of $X$, blend and block copolymer membranes.

\subsection{Mechanical Properties}

Generally, the interactions between polymer backbones can be weaker due to absorbed free water molecules. Accordingly, the tensile stiffness of PEMs is lower in the wet condition compared to dry 
condition. Therefore, the tensile stiffness and elongation break of the membranes were measured in dry condition at room temperature (Figure 8). The mechanical integrity of PEEK is admirable in dry state; however, once the PEEK chain was grafted with $\mathrm{SO}_{3} \mathrm{H}$ groups, a lower mechanical integrity was occurred due to the plasticization effect. Tensile strength and elongation break for SPEEK membrane in are $44.5 \mathrm{MPa}$ and $6.5 \%$, respectively. Both of them were enhanced significantly after attachment of the hydrophobic oligomer via block copolymerization. These results demonstrate that the prepared diblock $(X Y)$ and triblocks ( $X Y X$ and $Y X Y$ ) are sufficiently robust for fuel cell applications. Nevertheless, corresponding blend membranes show lower tensile strength and elongation break.
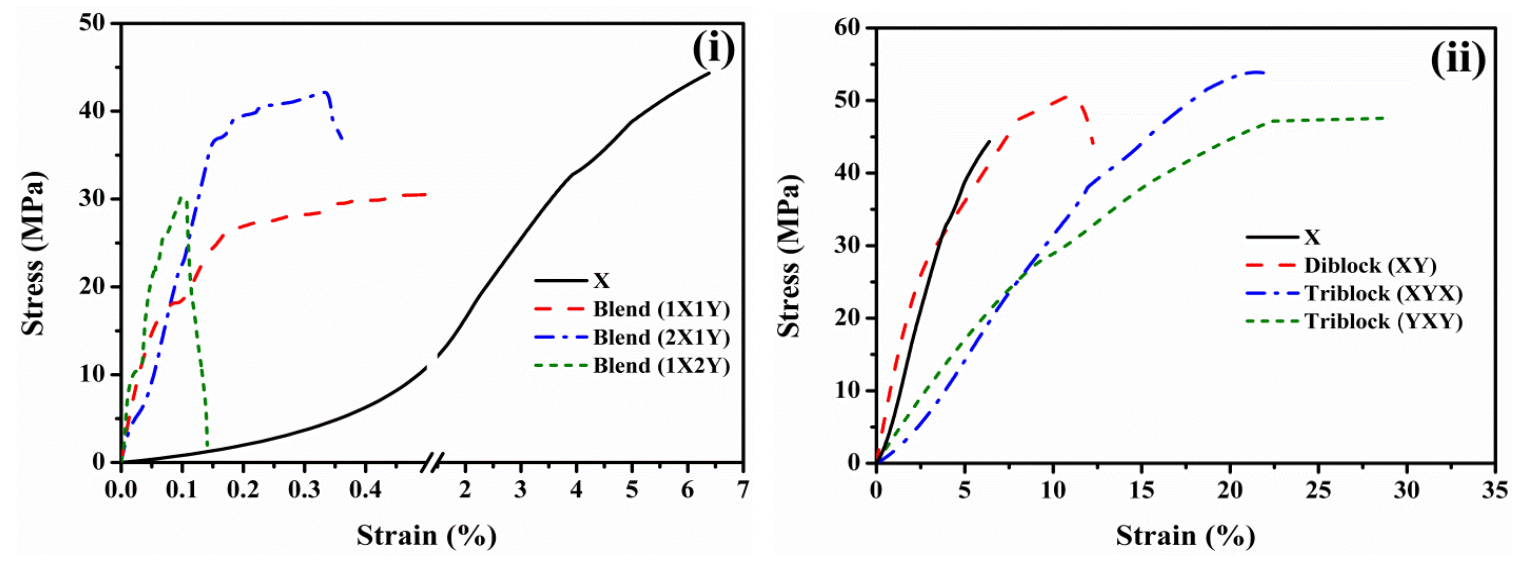

Figure 8. UTM stress-strain curves of (i) blend and (ii) block copolymer membranes.

\subsection{Proton Conductivity, Arrhenius Plot, and Water Uptake}

The proton conductivities of block copolymer and blend membranes were measured to investigate the hydrophobic oligomer effects (Figure 9). Conductivity of the triblock (XYX) membrane, $13.9 \mathrm{mS} \mathrm{cm}^{-1}$ to $108.1 \mathrm{mS} \mathrm{cm}^{-1}$ when increase the temperature from 20 to $80{ }^{\circ} \mathrm{C}$, was significantly greater than that of the diblock (XY) membrane, $11.1 \mathrm{mS} \mathrm{cm}^{-1}$ to $79.2 \mathrm{mS} \mathrm{cm}^{-1}$. The triblock (YXY) type displayed a maximum conductivity of $59.2 \mathrm{mS} \mathrm{cm}^{-1}$ at $80{ }^{\circ} \mathrm{C}$ due to the existence of a low hydrophilic ratio in PEM compared to the $\mathrm{XYX}$ and $\mathrm{XY}$ membranes. On other side, the conductivity of block copolymer membranes is better compared to blend membranes, which might be due to the regular architecture of conducting channels caused by multi-block structure. Since the blend membranes have more $-\mathrm{SO}_{3} \mathrm{H}$ groups, it seems the conducting channels of blend membranes were not regular and wide. For the case of $X$, the conducting channels are narrower and unconnected. Thus, the conductivity of $X$ is lower even when the degree of sulfonation is higher. The conductivity of $X Y X$ and $X Y$ membranes is also better compared to $\mathrm{X}$ membrane, which is due to the ordered and extended conducting channels caused by block structure. Activation energies $\left(\mathrm{E}_{\mathrm{a}}\right)$ of the ion conductivity values were calculated from Arrhenius plots using the Arrhenius formula [32-36].

$$
\ln \sigma=\ln \sigma_{0}-\frac{E_{a}}{R T}
$$

where $\sigma$ and $\sigma_{0}$ are proton conductivity and pre-exponential factor, respectively (in $\mathrm{mS} / \mathrm{cm}$ ), $E_{a}$ is the activation energy (in $\mathrm{kJ} / \mathrm{mol}$ ), $R$ is the gas constant (in $\mathrm{J} / \mathrm{molK}$ ), and $T$ is the absolute temperature (in $\mathrm{K}$ ). The XYX, XY, and YXY demonstrated $\mathrm{E}_{\mathrm{a}}$ of $15.1,18.3$ and $20.5 \mathrm{KJ} \mathrm{mol}^{-1}$, respectively (Table 2). The water retention properties of the membranes were evaluated from the weight change of the membrane before and after water uptake (Table 2). YXY is a more hydrophobic type of copolymer membrane, which can absorb only a small volume of water, while a larger number of ionic sites are responsible for higher water intake of the XYX membrane [37]. The swelling ratio of membranes is directly proportional to water uptakes. $\mathrm{XYX}$ membrane exhibits high swelling due to high water uptake (Table 2). 

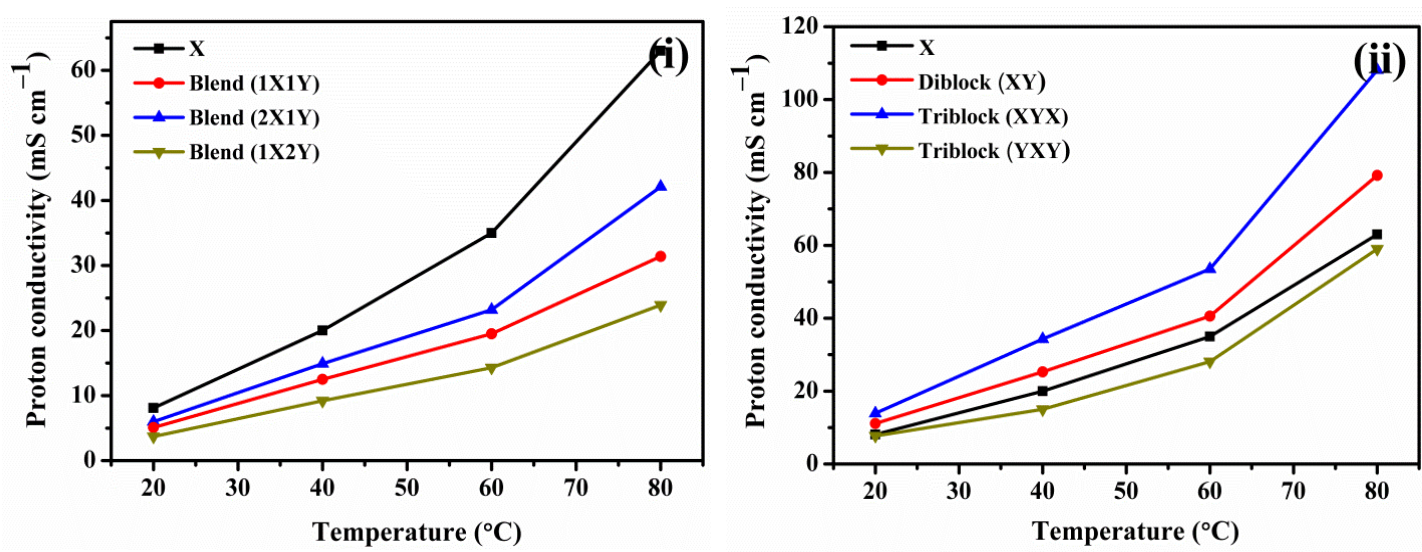

Figure 9. Proton conductivity plots of (i) blend and (ii) block copolymer membranes measured under $100 \%$ RH.

Table 2. Water uptake, swelling ratio, and activation energy of prepared membranes

\begin{tabular}{cccc}
\hline Membrane & Water Uptake (\%) & Swelling Ratio (\%) & Activation Energy (E $\left.\mathbf{E}_{\mathbf{a}}\right)$ \\
\hline X & 23.1 & 17.6 & 11.3 \\
XYX & 18.3 & 13.6 & 15.1 \\
XY & 12.2 & 9.4 & 18.3 \\
YXY & 7.6 & 4.4 & 20.5 \\
\hline
\end{tabular}

\subsection{PEFC Performance}

Figure 10 presents the single cell activities of PEFC comprised of blend and block copolymer membranes at $60^{\circ} \mathrm{C}$ under intermediate $(60 \%) \mathrm{RH}$ and atmospheric pressure. The good open circuit voltage of block copolymer ( $\mathrm{YXY}, \mathrm{XY}$, and $\mathrm{XYX}$ ) membranes indicates that $\mathrm{H}_{2}$ permeability across the membrane is lesser, which might the avoid loss of fuel and mixed potentials with $\mathrm{O}_{2}$. The triblock (XYX) membrane delivered a peak power density of $229 \mathrm{~mW} \mathrm{~cm}^{-2}$ at a load current of $393 \mathrm{~mA} \mathrm{~cm}$, which is 1.6 times greater than that of the blend $(\mathrm{XYX})$ membrane that delivered only a peak power density of $142 \mathrm{~mW} \mathrm{~cm}{ }^{-2}$ at a load current of $287 \mathrm{~mA} \mathrm{~cm}^{-2}$. The excess of ion conducting channels in the multi-block copolymer structure performs as a proton conducting medium, which enables the membrane to achieve high proton conductivity. The intermolecular hydrogen bonds formed between $\mathrm{SO}_{3} \mathrm{H}$ groups of the triblock (XYX) chains assist to form complex structures along the cross section of the membrane, blocking the passage of $\mathrm{H}_{2}$ gas and reducing $\mathrm{H}_{2}$ gas permeability. A cumulative effect of the aforesaid two factors is responsible for the high power density of the triblock (XYX) membrane. Table 3 demonstrates the comparison table of current study with other literatures.
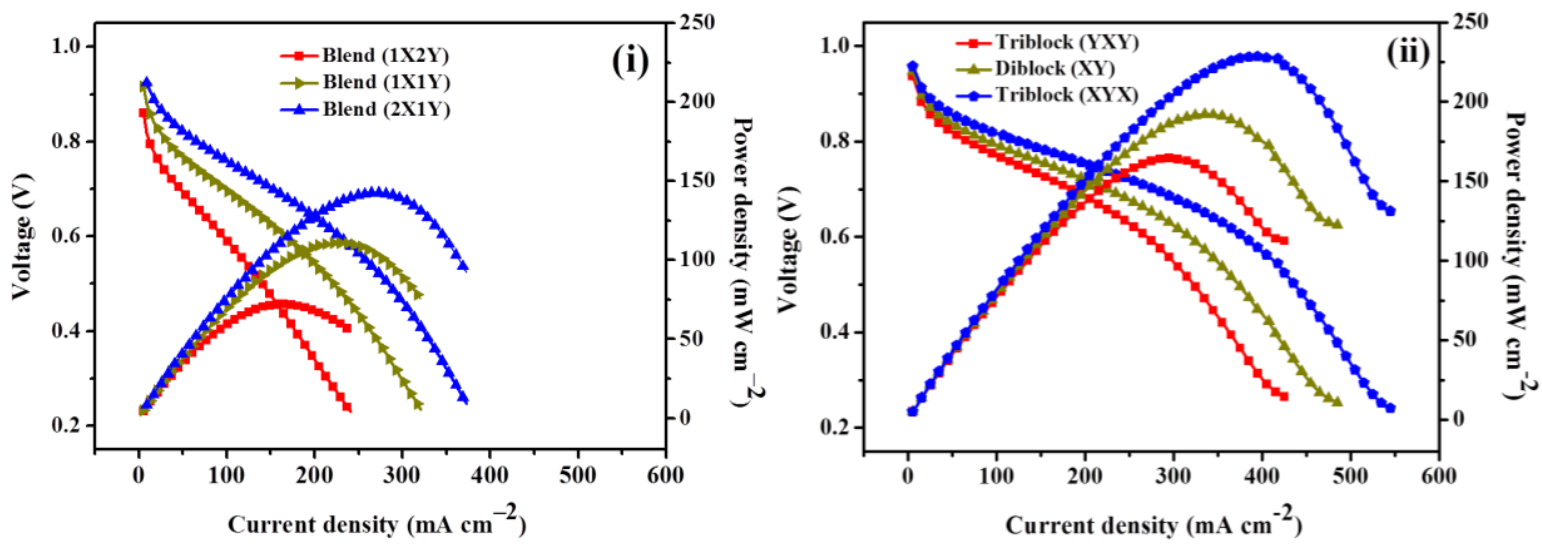

Figure 10. $\mathrm{H}_{2} / \mathrm{O}_{2}$ PEFC curves of (i) blend and (ii) block copolymer membranes evaluated at $60{ }^{\circ} \mathrm{C}$ under $60 \% \mathrm{RH}$. 
Table 3. Comparison table of performance of various block copolymer PEMs

\begin{tabular}{|c|c|c|c|c|c|}
\hline \multirow[b]{2}{*}{ Membrane } & \multirow{2}{*}{$\begin{array}{l}\text { Peak Current } \\
\text { Density } \\
\left.(\mathrm{mA} \mathrm{cm})^{-2}\right)\end{array}$} & \multirow{2}{*}{$\begin{array}{l}\text { Peak Power Density } \\
\qquad\left(\mathrm{mW} \mathrm{cm} \mathrm{cm}^{-2}\right)\end{array}$} & \multicolumn{2}{|c|}{ Operating Conditions } & \multirow[b]{2}{*}{ Reference } \\
\hline & & & $\begin{array}{c}\text { Relative Humidity } \\
(\%)\end{array}$ & $\begin{array}{c}\text { Temperature } \\
\left({ }^{\circ} \mathrm{C}\right)\end{array}$ & \\
\hline Triblock (XYX) & 550 & 229 & 60 & 60 & This work \\
\hline Block-30 & - & - & - & - & [30] \\
\hline sPAS-12/4 & 980 & - & 100 & 70 & [38] \\
\hline SPB/PAE & 1200 & - & 100 & 80 & [39] \\
\hline sPP-b-PAES (6.5k)-3.0 & 1920 & 780 & 100 & 70 & [40] \\
\hline sPEEK-b-sPB (I-4) & - & - & - & - & [41] \\
\hline SMBP-17 & 1210 & 410 & 100 & 80 & [42] \\
\hline
\end{tabular}

\section{Conclusions}

In summary, we present novel copolymer structures containing SPEEK (derived from commercially available PEEK) and artificial hydrophobic units to boost the thermal and mechanical properties of PEMs. Compared to blend (XYX), such a novel polymer structure of optimized triblock (XYX) membrane has brought a significant improvement in thermal stability. Being extended and continuously connected SPEEK chains formed in the XYX PEMs, the mechanical strength was elevated obviously. The triblock $(X Y X)$ constructs successive and effective conducting channels, which dramatically increase the proton conductivity of the membrane. In particular, the triblock (XYX) structure exhibits extended ion transport channels and shorter ion transport distances compared to traditional SPEEK and blend (2X1Y) PEMs, thus the PEFC performance of triblock (XYX) membrane was elevated significantly even under $60 \% \mathrm{RH}$. This work presents informative data relevant to the synthesis of new block copolymer structures containing SPEEK for use in high performance PEMs.

Supplementary Materials: The following are available online at http:/ / www.mdpi.com/2073-4360/10/12/1346/ s1, Figure S1: SAXS patterns of SPEEK, blend and block copolymer membranes; Figure S2: DSC curves of SPEEK and block copolymer membranes.

Author Contributions: A.R.K. prepared the polymers and PEMs, performed and analyzed the ${ }^{1}$ H-NMR, FE-SEM, AFM, TGA, UTM, water contact angle, proton conductivity and PEFC. M.V. wrote the paper and contributed to data analysis. C.J.P. contributed to the analysis of water uptake, swelling ratio, and IEC studies and PEMs. D.J.Y. contributed to manuscript preparation.

Acknowledgments: This work was supported by the Korea Institute of Energy Technology Evaluation and Planning (KETEP) and the Ministry of Trade, Industry \& Energy (MOTIE) of the Republic of Korea (No. 20184030202210). This research was supported by Basic Science Research Program through the National Research Foundation of Korea (NRF) funded by the Ministry of Science, ICT and future Planning (No. 2017R1A2B4005230).

Conflicts of Interest: The authors declare no conflict of interest.

\section{References}

1. Weber, A.Z.; Newman, J. Modeling. Transport in polymer-electrolyte fuel cells. Chem. Rev. 2004, 104, 4679-4726. [CrossRef]

2. Kodama, K.; Jinnouchi, R.; Takahashi, N.; Murata, H.; Morimoto, Y. Activities and stabilities of Au modified stepped-Pt single-crystal electrodes as model cathode catalysts in polymer electrolyte fuel cells. J. Am. Chem. Soc. 2016, 138, 4194-4200. [CrossRef]

3. Yao, Z.; Cui, M.; Zhang, Z.; Wu, L.; Xu, T. Silane cross-linked sulfonted poly(ether ketone/ether benzimidazole)s for fuel cell applications. Polymers 2017, 9, 631.

4. Chen, B.K.; Wu, T.Y.; Wong, J.M.; Chang, Y.M.; Lee, H.F.; Huang, W.Y.; Chen, A.F. Highly sulfonated diamine synthesized polyimides and protic ionic liquid composite membranes improve PEM conductivity. Polymers 2015, 7, 1047-1065. [CrossRef]

5. Hasani-Sadrabadi, M.M.; Emami, S.H.; Ghaffarian, R.; Moaddel, H. Nanocomposite membranes made from sulfonated poly(ether ether ketone) and montmorillonite clay for fuel cell applications. Energ. Fuels 2008, 22, 2539-2542. [CrossRef]

6. Miyatake, K.; Chikashige, Y.; Higuchi, E.; Watanabe, M. Tuned polymer electrolyte membranes based on aromatic polyethers for fuel cell applications. J. Am. Chem. Soc. 2007, 129, 3879-3887. [CrossRef] 
7. Assumma, L.; Nguyen, H.D.; Iojoiu, C.; Lyonnard, S.; Mercier, R.; Espuche, E. Effects of block length and membrane processing conditions on the morphology and properties of perfluorosulfonated poly(arylene ether sulfone) multi-block copolymer membranes for PEMFC. ACS Appl. Mater. Interfaces 2015, 7, 13808-13820. [CrossRef]

8. Ko, T.; Kim, K.; Lim, M.Y.; Nam, S.Y.; Kim, T.H.; Kim, S.K.; Lee, J.C. Sulfonated poly(arylene ether sulfone) composite membranes having poly(2,5-benzimidazole)-grafted graphene oxide for fuel cell applications. J. Mater. Chem. A 2015, 3, 20595-20606. [CrossRef]

9. Baker, A.M.; Wang, L.; Johnson, W.B.; Prasad, A.K.; Advani, S.G. Nafion membranes reinforced with ceria-coated multiwall carbon nanotubes for improved mechanical and chemical durability in polymer electrolyte membrane fuel cells. J. Phys. Chem. C 2014, 118, 26796-26802. [CrossRef]

10. Zhao, Y.; Li, X.; Wang, S.; Li, W.; Wang, X.; Chen, S.; Chen, J.; Xie, X. Proton exchange membranes prepared via atom transfer radical polymerization for proton exchange membrane fuel cell: Recent advances and perspectives. Int. J. Hydrog. Energy 2017, 42, 30013-30028. [CrossRef]

11. Tsai, L.D.; Chien, H.C.; Wang, C.H.; Lai, C.M.; Lin, J.N.; Zhu, C.Y.; Chang, F.C. Poly(ethylene glycol) modified activated carbon for high performance proton exchange membrane fuel cells. Int. J. Hydrog. Energy 2013, 38, 11331-11339. [CrossRef]

12. Assumma, L.; Iojoiu, C.; Ari, G.A.; Cointeaux, L.; Sanchez, J.Y. Polyethersulfone containing sulfonimide groups as proton exchange membrane fuel cells. Int. J. Hydrog. Energy 2014, 39, 2740-2750. [CrossRef]

13. Sahu, A.K.; Ketpang, K.; Shanmugam, S.; Kwon, O.; Lee, S.; Kim, H. Sulfonated graphene-Nafion composite membranes for polymer electrolyte fuel cells operating under reduced relative humidity. J. Phys. Chem. C 2016, 120, 15855-15866. [CrossRef]

14. Yang, C.; Srinivasan, S.; Bocarsly, A.B.; Tulyani, S.; Benziger, J.B. A comparison of physical properties and fuel cell performance of Nafion and zirconium phosphate/Nafion composite membranes. J. Membr. Sci. 2004, 237, 145-161. [CrossRef]

15. Ramani, V.; Kunz, H.R.; Fenton, J.M. Stabilized heteropolyacid/Nafion composite membranes for elevated temperature/low relative humidity PEFC operation. Electrochim Acta 2005, 50, 1181-1187.

16. Lee, K.H.; Chu, J.Y.; Kim, A.R.; Nahm, K.S.; Kim, C.J.; Yoo, D.J. Densely sulfonated block copolymer composite membranes containing phosphotungstic acid for fuel cell membranes. J. Membr. Sci. 2013, 434, 35-43. [CrossRef]

17. Vinothkannan, M.; Kim, A.R.; Nahm, K.S.; Yoo, D.J. Ternary hybrid (SPEEK/SPVdF-HFP/GO) based membrane electrolyte for the applications of fuel cells: Profile of improved mechanical strength, thermal stability and proton conductivity. RSC Adv. 2016, 6, 108851-108863. [CrossRef]

18. He, Y.; Tong, C.; Geng, L.; Liu, L.; Lü, C. Enhanced performance of the sulfonated polyimide proton exchange membranes by graphene oxide: Size effect of graphene oxide. J. Membr. Sci. 2014, 458, 36-46. [CrossRef]

19. Lee, K.H.; Chu, J.Y.; Kim, A.R.; Yoo, D.J. Enhanced performance of a sulfonated poly(arylene ether ketone) block copolymer bearing pendant sulfonic acid groups for polymer electrolyte membrane fuel cells operating at $80 \%$ relative humidity. ACS Appl. Mater. Interfaces 2018, 10, 20835-20844. [CrossRef]

20. Wang, F.; Hickner, M.; Kim, Y.S.; Zawodzinski, T.A.; McGrath, J.E. Direct polymerization of sulfonated poly(arylene ether sulfone) random (statistical) copolymers: Candidates for new proton exchange membranes. J. Membr. Sci. 2002, 197, 231-242. [CrossRef]

21. Kim, A.R.; Vinothkannan, M.; Yoo, D.J. Artificially designed, low humidifying organic-inorganic (SFBC-50/FSiO2) composite membrane for electrolyte applications of fuel cells. Compos. Part B-Eng. 2017, 130, 103-118. [CrossRef]

22. Vinothkannan, M.; Kim, A.R.; Kumar, G.G.; Yoon, J.-M.; Yoo, D.J. Toward improved mechanical strength, oxidative stability and proton conductivity of an aligned quadratic hybrid (SPEEK/FPAPB $/ \mathrm{Fe}_{3} \mathrm{O}_{4}-\mathrm{FGO}$ ) membrane for application in high temperature and low humidity fuel cells. RSC Adv. 2017, 7, 39034-39048. [CrossRef]

23. Gahlot, S.; Kulshrestha, V. Dramatic improvement in water retention and proton conductivity in electrically aligned functionalized CNT/SPEEK nanohybrid PEM. ACS Appl. Mater. Interfaces 2015, 7, $264-272$. [CrossRef]

24. Xing, P.; Robertson, G.P.; Guiver, M.D.; Mikhailenko, S.D.; Wang, K.; Kaliaguine, S. Synthesis and characterization of sulfonated poly(ether ether ketone) for proton exchange membranes. J. Membr. Sci. 2004, 229, 95-106. [CrossRef] 
25. Ketpang, K.; Lee, K.; Shanmugam, S. Facile synthesis of porous metal oxide nanotubes and modified nafion composite membranes for polymer electrolyte fuel cells operated under low relative humidity. ACS Appl. Mater. Interfaces 2014, 6, 16734-16744. [CrossRef]

26. Parnian, M.J.; Rowshanzamir, S.; Prasad, A.K.; Advani, S.G. High durability sulfonated poly (ether ether ketone)-ceria nanocomposite membranes for proton exchange membrane fuel cell applications. J. Membr. Sci. 2018, 556, 12-22. [CrossRef]

27. Kim, A.R.; Vinothkannan, M.; Yoo, D.J. Sulfonated-fluorinated copolymer blending membranes containing SPEEK for use as the electrolyte in polymer electrolyte fuel cells (PEFC). Int. J. Hydrog. Energy 2017, 42, 4349-4365. [CrossRef]

28. Mishra, A.K.; Kim, N.H.; Jung, D.; Lee, J.H. Enhanced mechanical properties and proton conductivity of Nafion-SPEEK-GO composite membranes for fuel cell applications. J. Membr. Sci. 2014, 458, 128-135. [CrossRef]

29. Gahlot, S.; Sharma, P.P.; Kulshrestha, V.; Jha, P.K. SGO/SPES-based highly conducting polymer electrolyte membranes for fuel cell application. ACS Appl. Mater. Interfaces 2014, 69, 5595-5601. [CrossRef]

30. Chu, J.Y.; Kim, A.R.; Nahm, K.S.; Lee, H.K.; Yoo, D.J. Synthesis and characterization of partially fluorinated sulfonated poly(arylene biphenylsulfone ketone) block copolymers containing 6F-BPA and perfluorobiphenylene units. Int. J. Hydrog. Energy 2013, 38, 6268-6274. [CrossRef]

31. Mohanty, A.K.; Mistri, E.A.; Banerjee, S.; Komber, H.; Voit, B. Highly fluorinated sulfonated poly(arylene ether sulfone) copolymers: Synthesis and evaluation of proton Exchange membrane properties. Ind. Eng. Chem. Res. 2013, 52, 2772-2783. [CrossRef]

32. Jiang, Z.; Zhao, X.; Fu, Y.; Manthiram, A. Composite membranes based on sulfonated poly(ether ether ketone) and SDBS-adsorbed graphene oxide for direct methanol fuel cells. J. Mater. Chem. 2012, 22, 24862-24869. [CrossRef]

33. Xu, C.; Cao, Y.; Kumar, R.; Wu, X.; Wang, X.; Scott, K. A polybenzimidazole/sulfonated graphite oxide composite membrane for high temperature polymer electrolyte membrane fuel cells. J. Mater. Chem. 2011, 11, 11359-11364. [CrossRef]

34. Zhao, L.; Li, Y.; Zhang, H.; Wu, W.; Liu, J.; Wang, J. Constructing proton-conductive highways within an ionomer membrane by embedding sulfonated polymer brush modified graphene oxide. J. Power Sources 2015, 286, 445-457. [CrossRef]

35. Li, Y.; Wang, J.; Zhang, H.; Ma, C.; Liu, J.; Cao, S.; Zhang, X. Enhancement of proton conductivity of chitosan membrane enabled by sulfonated graphene oxide under both hydrated and anhydrous conditions. J. Power Sources 2014, 269, 898-911. [CrossRef]

36. Gahlot, S.; Gupta, H.; Jha, P.K.; Kulshrestha, V. Enhanced electrochemical performance of stable SPES/SPANI composite polymer electrolyte membranes by enriched ionic nanochannels. ACS Omega 2017, 2, 5831-5839. [CrossRef]

37. Beers, K.M.; Balsara, N.P. Design of cluster-free polymer electrolyte membranes and implications on proton conductivity. ACS Macro Lett. 2012, 1, 1155-1160. [CrossRef]

38. Jung, M.S.; Kim, T.H.; Yoon, Y.J.; Kang, C.G.; Yu, D.M.; Lee, J.Y.; Kim, H.J.; Hong, Y.T. Sulfonated poly (arylene sulfone) multiblock copolymers for proton exchange membrane fuel cells. J. Membr. Sci. 2014, 459, 72-85. [CrossRef]

39. Miyahara, T.; Hayano, T.; Matsuno, S.; Watanabe, M.; Miyatake, K. Sulfonated polybenzophenone / poly(arylene ether) block copolymer membranes for fuel cell applications. ACS Appl. Mater. Interfaces 2012, 4, 2881-2884. [CrossRef]

40. Lee, J.Y.; Yu, D.M.; Kim, T.H.; Yoon, S.J.; Hong, Y.T. Multi-block copolymers based on poly(p-phenylene)s with excellent durability and fuel cell performance. J. Membr. Sci. 2015, 492, 209-219. [CrossRef] 
41. Zhao, Y.; Yin, J. Synthesis and evaluation of all-block-sulfonated copolymers as proton exchange membranes for fuel cell application. J. Membr. Sci. 2010, 351, 28-35. [CrossRef]

42. Lim, Y.D.; Seo, D.W.; Lee, S.H.; Hossain, M.A.; Kang, K.; Ju, H.; Kim, W.G. Synthesis and characterization of sulfonated poly (arylene ether ketone sulfone) block copolymers containing multi-phenyl for PEMFC. Int. J. Hydrog. Energy 2013, 38, 631-639. [CrossRef] 